\title{
Developing Safe Care in Mental Health for Children and Young People: Drawing on UK Experience for Solutions to an Under-Recognised Problem
}

Daniel Hayes, BSC, MSC ${ }^{1}$

Isobel Fleming, PhD ${ }^{2}$

Miranda Wolpert, PsychD ${ }^{1, *}$

\author{
Address \\ ${ }^{*}, 1$ Evidence Based Practice Unit, University College London and Anna Freud \\ Centre, 21 Maresfield Gardens, London, NW3 5SD, UK \\ Email: ebpu@annafreud.org \\ ${ }^{2}$ Child Outcome Research Consortium (CORC), 4-8 Rodney Street, London, N1 9JH, UK
}

Published online: 20 0ctober 2015

(C) Springer International Publishing AG 2015

This article is part of the Topical Collection on Patient Safety

Keywords Harm · Safety · Child mental health - Adolescent mental health

\section{Opinion statement}

Safe care in child and adolescent mental health is an under-developed concept. A new model for conceiving of potential harm and embedding a safety culture has been suggested, which comprises three levels of harm and a range of initiatives designed to promote safety. At the first level, harm may be caused by lack of engagement with appropriate help; this is a critical issue for child mental health where key barriers include stigma, lack of knowledge and, crucially, lack of provision. Initiatives to address barriers to help-seeking include online tools for education and/or support. Once in contact with services, premature disengagement must be carefully monitored, particularly when this is mediated by parent/carer choice when it may be considered as a safeguarding issue.

At the second level, harm may be caused by ineffective practice. Effective practice is increasingly conceived as involving a combination of evidence-based practice, service user preference, and regular review of outcomes and feedback. Initiatives involving collaborations of service providers to work to common standards in line with best practice are increasingly aligned and collaboratively seek to support best practice in this regard. However, this needs to be supported by adequate staffing and infrastructure for safe 
practice. At the third level, harm may be caused by adverse events. Serious case reviews following a major incident or child death have highlighted possibilities of key learning such as the need for greater review of integration of services, and there is an emerging research agenda looking at the iatrogenic impact of talking therapies. Using and integrating national and international data sets should help support the review of such issues, and the emergence of new models of care and payment system work will provide opportunities for setting in place mechanisms to minimise adverse events and embed a more explicitly safety-focused culture.

\section{Introduction}

Internationally, safety of care in child and adolescent mental health has received limited attention. Attempts to understand this area have mainly focused on issues of safety in relation to safeguarding [1] on the one hand, or lack of access to services [2] on the other. There is a call for clinicians, service developers and researchers to consider harm and safety more generally in child and adolescent

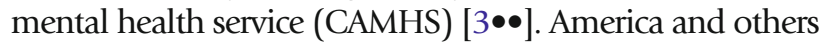
have begun to initiate discussions on the possibility of harm caused by psychotherapy [4, 5]; however, the lack of shared definitions as to what constitutes safety and harm present ongoing challenges $[3 \bullet \bullet, 4]$. To start to rise


framework for considering harm in relation to child and adolescent mental health provision in Fig. 1.
Within the framework, safety and harm are considered in relation to terms of three aspects:

1. Ineffective engagement-whether through lack of services available or through lack of uptake of existing services;

2. Ineffective practice-examples of which include the prescription of non-evidence-based treatments or a breach within accepted guidelines such as waiting times;

3. Adverse events-where clear negative outcomes are associated with particular events, such as youth death, including suicide.

The latest findings and developments in each of these three areas are considered below, as well as key
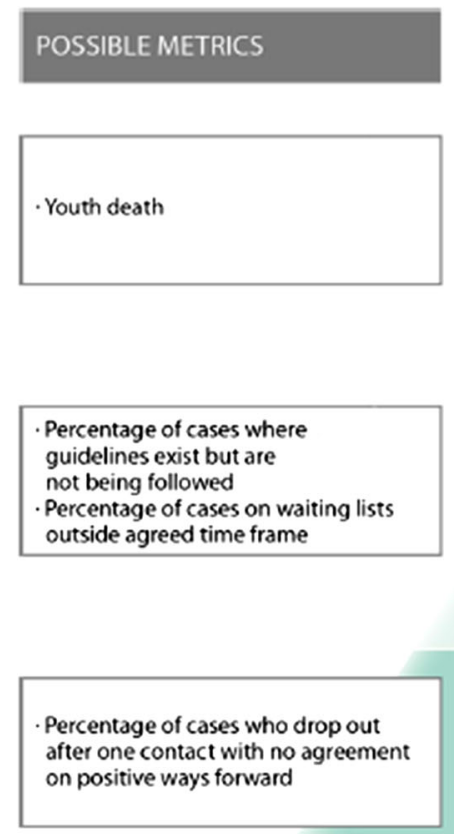

POSSIBLE KEY IMPLICATED AREAS FOR IMPROVEMENT

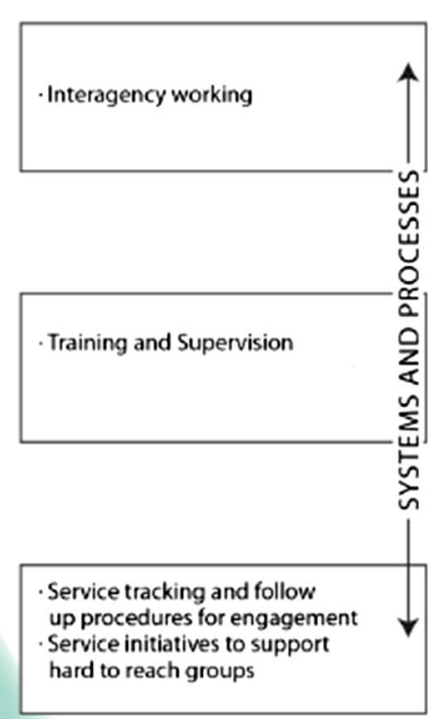

Fig. 1. Framework for consideration of patient safety in child and adolescent mental health. 
interventions that have been developed within the UK at each level (Tables 1, 2 and 3).

\section{Safety in relation to service engagement}

Global prevalence rates suggest that around $25 \%$ of young people experience mental health issues, with fewer than half receiving mental health specialist treatment [6]. There is also evidence of growing rates of mental health difficulties, particularly emotional problems in teenage girls [7] and increased rates of self-harm being reported over the last decade [8]. Within the UK, these increases are occurring alongside concurrent extensive disinvestment in specialist provision with many areas already experiencing $25 \%$ cuts in funding [9], and less than half of CAMHS reporting being able to provide appropriate crisis access for young people $[9,10]$. Thus, the primary safety issue is the need to consider safety for those young people not able to even currently access services.

For those not accessing specialist mental health services, there is some evidence that they do draw on educational support and/or primary care [11, 12]. Schools are increasingly looked to as a site for future work for mental health promotion and intervention [13], but there is a need for greater clarity on what works

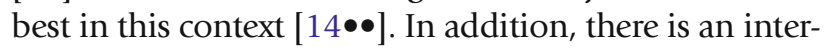
est in increasing access by use of online resources, such as online counselling and support [15], though the efficacy remains unclear [16].

Harm from ineffective engagement may also occur when service provision is available, but young people fail to make use of what is on offer. For those young people who choose not to access services, reasons include fear and stigma $[17,18]$. Increased education around mental health literacy may improve this [19].

In addition, a lack of knowledge about how and where to access services may also affect whether people attend [18]. There are an increasing number of websites to aid people finding help such as Find Get Give (http:// www.findgetgive.com), the Youth Wellbeing Directory (http://www.youthwellbeingdirectory.co.uk), ReachOut (http://www.reachoutuk.org) and MyCAMHSChoices (http://mycamhschoices.org). A systematic review into online help suggests that young people view websites favourably, stating they were satisfactory and they would use them again or recommend to a friend. However, more research needs to be undertaken to establish whether online services increase help-seeking behaviour [20].

To tackle current issues with service provision and reduce the risk of harm, increased investment is needed, as well as new ways of maximising existing resources. Novel models of service provision include that of THRIVE, which reconceptualises CAMHS into resourcehomogenous groups based on their needs, as well as drawing distinctions between treatment and support, and between self-management and intervention [21]. Aligned with this, work from payment systems in CAMHS also highlights distinct needs-based groupings for those seeking help and support [22]. Reorganising services according to such frameworks may allow for more transparent discussions between providers and users, options for more targeted performance management and potential for more targeted funding which could help with service engagement [23].

Another barrier to engagement with help is people dropping out of treatment prematurely. Attempts to increase attendance rates have focused on reminding service users, or having opt-in appointments. Drawing on data from both adult and child mental health populations, research suggests that when utilising an opt-in system, median non-attendance rates fall from around $27 \%$ to around $4 \%$ [24]. However, opt-in systems may not tackle underlying barriers to non-engagement

\section{Table 1. UK interventions for harm caused by lack of engagement with appropriate help}

\section{Possible interventions for harm caused by lack of engagement with appropriate help}

Websites to aid people finding help such as Find Get Give, the Youth Wellbeing Directory, ReachOut and MyCAMHSChoices Novel ways of service conceptualisation and provision such as those outlined in THRIVE [23] and CAMHS Payment Systems [22] Opt-in systems for appointment attendance [24]

Engaging patients and caregivers prior to initial appointment attendance [25•]

Reconceptualisation of 'Did not attend' (DNA) to 'Was not brought' (WNB) in healthcare settings [27•]

Engaging and allowing participation of young people in healthcare (shared decision-making) [37-40] 
[24] and may exclude those who need treatment such as those undecided or scared about attending [25•].

Engaging parents prior to a CAMHS appointment may be useful as it can provide the opportunity for clinicians and parents to discuss opportunities and barriers to attendance. In one study, in which a key worker contacted the parent/guardian to discuss items such as why the referral was made and logistics in getting to CAMHS, appointment non-attendance was significantly less likely than compared to the two control groups [25•]. Moreover, this intervention was found to have similar outcomes regardless of ethnicity and deprivation level $[25 \bullet]$.

For children, dropping out prematurely from treatment may be considered a safeguarding issue, as attendance may be considered to be in the best interests of the child [26]. Moreover, non-attendance may be the result of the parent or carer rather than child choice [27•]. Missed appointments have been highlighted as a warning sign in a number of serious case reviews and child death reviews $[27 \bullet]$.

Developing safe care in mental health for children and young people thus requires the understanding and reinforcement of guidelines around missed appointments and safeguarding. There is evidence of inconsistencies and variability as to what should and does happen following a missed appointment in NHS organisations [28], as well as staff being unsure what the guidelines are [29]. Some academics have proposed a change in guidelines suggesting the 'catch all' category of did not attend (DNA) distorts the nature of non-attendance [27•]. Instead, the term 'was not brought' (WNB) has been suggested, in order to highlight the lack of autonomy and dependence of the child or young person, as well as potentially leading healthcare professionals to consider why the child was not brought [27•].

Young people who drop out of treatment early are more likely to experience continuing mental health difficulties and functional impairment when compared to those who stay in and finish treatment [30-33]. Satisfaction with the service, both for young people and for parents/guardians, is an important predictor of engagement and treatment completion [34], yet young people and parents do not feel listened to $[35,36]$ and state that they find a lack of continuity of care unhelpful [18].

One approach that may address disengagement with services is an emphasis on shared decision making [37]. This is an interactive process during which patients and practitioners collaborate in choosing healthcare, and sees the the patient as an expert about themselves and a clinician as an expert in the treatment [38]. Its application to CAMHS is still in its infancy, yet tools and approaches implementing shared decision making may increase knowledge, improve clinical outcomes and may be useful in facilitating conversations about values and treatment options [37, 39, 40]. Common engagement approaches such as assessment, accessibility promotion, psychoeducation about services, homework assignment and appointment reminders may also be a way of keeping young people and families in services [41]. A review of common elements of successful treatment engagement within CAMHS suggests that assessment and accessibility (defined as 'measuring a client's strengths/needs through a variety of methods' and 'any strategy used to make services convenient and accessible in order to increase participation in treatment', respectively) were consistently associated with positive outcomes, such as attendance and adherence [41].

Another way of addressing some of the concerns of young people's lack of satisfaction with services could be through using frameworks such as the common assessment framework (CAF). An investigation by the Local Authorities Research Committee (LARC) found that CAF improved outcomes for young people and their families by treating them as equal partners, as well as providing a consistent lead professional, which facilitated better working relationships between professionals and service users [40]. Local authorities also emphasised the need to engage young people and their families, and reported positive benefits in doing so, including young people and their families better understanding their own and other's needs, improved parenting skills and techniques, improved relationships between families and professionals and new opportunities for multi-agency professionals to work with parents [40].

\section{Safety in relation to ineffective practice}

Worldwide, there is a shortage of trained professionals working in child and adolescent mental health; this is particularly true in developing countries where there are not enough professionals trained in basic child mental health treatments [42]. In the UK, CAMHS staff traditionally provided a wide variety of interventions with little standardisation. Concerns have also been raised about a range of practices that may be limiting 
effectiveness of intervention in the UK [43, 44]. Up until recently, most practitioners had not received training in some interventions with the strongest evidence base [44, 45]. Moreover, there is evidence that the majority of people accessing services are being seen for a shorter amount of contact time than recommended in best practice guidance [46], though it is not yet clear how far this relates to patient choice. The setting up of practice research networks (PRN) and collaborations such as the learning collaboration of CAMHS providers led by two of the authors of this paper-Child Outcomes Research Consortium (CORC) - may be a way of bridging the gap between researcher and clinicians, focusing attention on potential for harm from ineffective practice, and developing effective practice by involving clinicians and increasing generalisability of findings [47]. However, for clinicians to be engaged in research, it must be clinically helpful to them [48]. This could be through the collection of data for monitoring the progress of a patient or using the outcome measures in supervision to reflect on practice $[49,50]$.

Over the past two years, best practice guidance has coalesced around the Children and Young People's Improving Access to Psychological Therapy programme (CYP IAPT) which has brought together a common model of best practice [51] through an emphasis on outcomes (highlighting session-bysession feedback and review), patient preferences (shared decision making) and the use of evidencebased therapies as recommended by the National

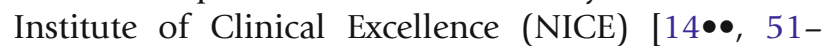
53]. Markers of value and quality have been identified and are quality assured, processed and accredited through a number of organisations and programmes including the Quality Network for Community CAMHS (QNCC), Youth Wellbeing Directory with ACE-V (ACE-Value) Quality Standards, Choice and
Partnership Approach (CAPA) and Child Outcome Research Consortium (CORC) [51]. Similar work addressing evidence-based programmes and practice is also being undertaken elsewhere such as by the Substance Abuse and Mental Health Services Administration (SAMHSA) in the United States.

However, what constitutes reasonable expectations of effective intervention and the possible harm from ineffective treatment (whether supported by the research evidence-base or not) remain under-discussed. There is no literature that we are aware of that considers the potential harm of loss of attendance at school, impact on self-image or self-esteem, or impact on relationships against the positive impact of any treatment, let alone the harm of being seen when treatment does not effect change $[3 \bullet \bullet]$.

Research suggests that evidenced-based youth psychotherapies demonstrate only a modest treatment effect and are moderated by youth location and assessment characteristics [54]. There is mixed evidence as to how far current service provision constitutes effective practice. International research into the effectiveness of routine CAMHS finds the majority of children receiving community-based standard care do not show clinical improvement $[55,56]$ and generally show less improvement than in RCT studies. Yet, there is little literature to guide clinicians about how to discuss treatment failures with children and families or how to decide when continuing to see someone is counter indicated.

A key focus in recent years has been on the use of routine outcome monitoring and patient feedback throughout therapy to consider how treatment is progressing and make changes as relevant. Whilst there is some work from Lambert, Bickman, Miller and others [57-59] tracking outcomes and considering off-track cases, there is still little developed

\section{Table 2. UK interventions for harm caused by ineffective practice}

\section{Possible interventions for harm caused by ineffective practice}

Setting up practice research networks (PRNs) as a way of bridging the gap between researchers and clinicians and generalising findings [47]

Using routine outcome monitoring (ROM) and session-by-session monitoring in supervision $[49,50]$

Initiation of accredited markers of quality and value in relation to effective practice as demonstrated organisations such as the Quality Network for Community CAMHS (QNCC), Youth Wellbeing Directory with ACE-V (ACE-Value) Quality Standards, Choice and Partnership Approach (CAPA) and CORC

Tracking patient outcome and process and considering off-track cases [53] 
literature on when to determine that treatment is failing and how to decide if another option would be more beneficial. Greater work is urgently needed in this regard.

\section{Safety in relation to adverse events}

The lack of a clear definition on what constitutes an adverse event in mental health, as well as how to adequately capture this in research and clinical practice, remains a challenge [4]. What we do know about adverse events is often drawn from serious case reviews, which have consistently show us that there is a need for stronger interagency working and collaboration around the sharing of information [27•].

Rather than outcomes from case reviews, wider learning mechanisms such as multi-agency training have been developed to try and clarify accountability and learning. Particular praise has been given to the MultiAgency Critical Incident Experience (MACIE) approach which aims to foster characteristics such as shared responsibility and strong leadership, challenge partner professionals and develop a common language through simulated cases [60]. Failure Modes and Effects Analysis (FMEA) has also been highlighted as a learning mechanism [60] as it can generate collective learning including identifying remedial actions that can prevent adverse events within complex and high-risk processes. FMEA has already been applied to domestic abuse and child protection, with it being found that it was useful in generating a map and applying corrective actions where possible, as well as reported enhanced multidisciplinary, multi-agency learning around domestic abuse, though it was time and resource intensive [61]. It has been suggested that paediatric nurses may want to use such an approach for child protection [62] but this could also be used in CAMHS.

A scoping review into the development of models and approaches to address the difficulties of interprofessional working between NHS and local authority social services identified a number of initiatives being trialled [63]. For multi-agency team work, it was found that the common assessment framework (CAF) formed an integral role, as it can be used to create an interprofessional group of 'virtual' professionals around the individual, including principal professionals to organise and facilitate care [63]. Other approaches identified included the co-location of professionals through MultiAgency Safeguarding Hubs (MASH) to facilitate information sharing [64]. Whilst there are some initial positive findings for MASH, such as better information sharing [63], it was concluded that for all new initiatives identified, there were too few studies to conclude their effectiveness, particularly for outcomes relating to young people and families [63]. The implementation of new multi-agency inspection frameworks in April 2015 [65] may help provide such evidence when data has been collected and analysed.

Approaches currently being used within CAMHS such as Adolescent Mentalization-Based Integrative Therapy (AMBIT) may also be useful to foster interagency collaboration and work with young people who have severe, multiple needs and who may not actively engage with professionals or access mainstream services [66, 67]. Initial evaluation of two team's that implemented AMBIT suggested that one teams' learning focused on an improved understanding of the client group, a change in perception of the effectiveness of the team and a change in attitude towards outcomes monitoring itself. The other team's learning highlighted improved explicit knowledge of core outcomes, making sense of different perspectives about outcomes and changing practices around what was not working [68].

Adapting existing approaches used in physical health may also improve safety through addressing a lack of information sharing and collaborative practice. One such approach is the huddle, which brings together staff to disseminate and share information in a fast, focused and collaborative way [69]. This brief and rapid exchange of information allows staff to prioritise the day's work, share information regarding patients, plan for

\section{Table 3. UK interventions for harm caused by adverse events}

\section{Possible interventions for harm caused by adverse events}

The implementation of wider learning mechanisms such as Multi-Agency Critical Incident Experience (MACIE) or Failure Modes and Effects Analysis (FMEA) to clarify leaning and accountability [60]

Addressing difficulties posed by multi-team working through using the common assessment framework (CAF) [63], Multi-Agency Safeguarding Hubs (MASH) [64], Huddles [69] or through programmes such as AMBIT [66] 
changes to patient flow and deal with staff adjustments [70]. Within paediatrics, results have been positive, with huddling being attributed to improved efficiencies and quality of information, sharing, increased levels of accountability, empowerment and sense of community, a lowering in 'unsafe transfers' and an increase of days between incidence $[71,72]$. Huddles are currently being trialled across a number of paediatric departments in English hospitals [73], and if successful, CAMHS teams may wish to adapt and trial it.

Understanding specific adverse events caused by psychological therapy is still under researched [5]. If psychotherapies have the potential to alleviate mental health issues, they must also have the potential to do the opposite as well [74]. Indeed, many CBT clinicians have observed adverse events from people they were treating [75]. An investigation into clinical trials involving psychological treatments found that reporting of adverse events caused by psychotherapy did not make it into any final reports, with the authors concluding that the National Research Ethics Service guidelines did not adequately capture this area [76]. Ideas about how to define and address such adverse events have been outlined $[4,77 \bullet \bullet]$.

Work being undertaken within this area includes the University of Sheffield's Adverse Effects of Psychological Therapies (AdEPT) project. Results have yet to be published, though findings will be limited in their application to CAMHS as AdEPT focuses on those aged over 18 and receiving psychological therapies. Moreover, with increasing emphasis of the use of online and electronic treatments in CAMHS [78], attention should also focus on harm caused by these modalities. Findings from one study have demonstrated negative effect effects brought on by internet interventions [79]. This may be particularly relevant to young people who have grown up with and are confident users of technology [80].

Countries collecting national data, such as the US through the Substance Abuse and Mental Health Services Administration (SAMHSA) and National Mental Health Services Survey (N-MHSS), may be able to use this data to better understand services treatment offered and forecast future requirements [81]. Within the UK, child and adolescent mental health data is planned to be collected by the Health and Social Care Information Centre (HSCIC) from January 2016 as part of the Mental Health Services Data Set (MHSDS). It is not yet clear when these data will be available for researchers; however, the lack of nationally available data has been highlighted in several key reports $[82,83]$ and is seen as critical to underpinning long-term sustained quality improvement across the health sector, education and social care [84].

\section{Conclusions/considerations}

Internationally, safe care in CAMHS has been until recently an under-developed concept. Within the UK, a number of interventions are being trialled which children and adolescents may benefit from. For example, new models for conceiving of potential harm and initiatives for embedding a safety culture in CAMHS are emerging. These include initiatives designed to address barriers to engagement with services, including greater use of online support, schools-based and online education about sources of help (e.g. MyCAMHSChoices, the Youth Wellbeing Directory and Find Get Give); initiatives designed to promote effective practice (conceived as requiring a combination of evidence-based practice, service user preference and regular review of outcomes and feedback) from UK sources (e.g. CYP IAPT, CORC, QNCC and CAPA) and abroad (e.g. the Substance Abuse and Mental Health Services Administration N-MHSS). Lastly, initiatives designed to review and address adverse events include the emerging research agenda considering the potential iatrogenic impact of talking therapies, such as that explored in the AdEPT study, and the more meaningful use of data across systems.

However, it should be noted that due to present levels of challenge and funding services, both in the UK and abroad, the risk of harm remains high. The 
emergence of new models and approaches to CAMHS, as exemplified by the THRIVE model [21] and emerging payment system work [22], provides opportunities for embedding these principles, supporting both values-based and value-based service delivery $[9,51]$ to ensure that consideration of safe care is at the heart of the future development of child mental health services. Whilst this initial work in the UK is encouraging, how this may translate to healthcare systems abroad remains unknown. As such, such initiatives should be piloted, and process and outcome measures observed before any formal implementation.

\section{Compliance with Ethical Standards}

\section{Conflict of Interest}

Daniel Hayes and Miranda Wolpert declare that they have no conflict of interest. Isobel Fleming was formerly Deputy Director of Child Outcomes Research Consortium.

Human and Animal Rights and Informed Consent

This article does not contain any studies with human or animal subjects performed by any of the authors.

\section{References and Recommended Reading}

Papers of particular interest; published recently; have been

highlighted as:

- Of importance

• Of major importance

1. Treatment Advocacy Center 2014. Retrieved June 01, 2014, from http://wwwtreatmentadvocacycenter.org/ index.php.

2. Campion J, Bhugra D, Bailey S, Marmot M. Inequality and mental disorders: opportunities for action. Lancet. 2013;382(9888):183-4.

3.• Wolpert M, Deighton J, Fleming I, Lachman P. Considering harm and safety in youth mental health: a call for attention and action. Adm Policy Ment Health Ment Health Serv Res. 2015;42(1):6-9.

This paper proposes a framework to begin to think about safety and harm in youth mental health.

4. Dimidjian S, Hollon SD. How would we know if psychotherapy were harmful? Am Psychol. 2010;65(1):21.

5. Nutt DJ, Sharpe M. Uncritical positive regard? Issues in the efficacy and safety of psychotherapy. J Psychopharmacol. 2008;22(1):3.

6. Merikangas KR, Nakamura EF, Kessler RC. Epidemiology of mental disorders in children and adolescents. Dialogues Clin Neurosci. 2009;11(1):7.

7. Fink E, Patalay P, Sharpe H, Holley S, Deighton J, Wolpert M. Mental health difficulties in early adolescence: a comparison of two cross-sectional studies in
England from 2009 to 2014. J Adolesc Health. 2015;56(5):502-7.

8. Chief Medical Officer's Annual Report. Our children deserve better: prevention pays: London: Department of Health 2012.

9. NHS Benchmarking Network. CAMHS benchmarking report December 2013. Retrieved from http://www. rcpsych.ac.uk/pdf/CAMHS\%20Report\%20Dec\% 202013\%20v1(1).pdf.2013.

10. Young Minds. Local authorities and CAMHS budgets 2012/2013: London: Young Minds. 2013.

11. Green H, McGinnity Á, Meltzer H, Ford T, Goodman R. Mental health of children and young people in Great Britain, 2004. Palgrave Macmillan Basingstoke; 2005

12. Meltzer H, Gatward R, Goodman R, Ford T. Mental health of children and adolescents in Great Britain. Int Rev Psychiatry. 2003;15(1-2):185-7.

13. Department for Education. Counselling in schools: a blueprint for the future London: Department for Education. 2015.

14.• Fonagy P, Cottrell D, Phillips J, Bevington D, Glaser D, Allison E. What works for whom?: a critical review of treatments for children and adolescents. Guilford Publications; 2014. 
This book provides a systematic review of the research evidence for treatment options in child and adolescent mental health.

15. Glasheen K, Shochet I, Campbell M. Online counselling in secondary schools: would students seek help by this medium? British Journal of Guidance \& Counselling. 2015(ahead-of-print):1-15.

16. National Collaborating Centre for Mental Health. Etherapies systematic review for children and young people with mental health problems. 2014.

17. Young Minds. Stigma: a review of the evidence: London: Young Minds. 2010.

18. Plaistow J, Masson K, Koch D, Wilson J, Stark RM, Jones $\mathrm{PB}$, et al. Young people's views of UK mental health services. Early interv Psychiatry. 2014;8(1):1223.

19. Gulliver A, Griffiths KM, Christensen H. Perceived barriers and facilitators to mental health help-seeking in young people: a systematic review. BMC Psychiatry. 2010;10(1):113.

20. Kauer SD, Mangan C, Sanci L. Do online mental health services improve help-seeking for young people? A systematic review. J Med Internet Res. 2014;16(3), e66. doi:10.2196/jmir.3103.

21. Wolpert M, Harris R, Jones M, Hodges S, Fuggle P, James R et al. THRIVE: The AFC-Tavistock Model for CAMHS. London: CAMHS Press. Available at: www. tavistockandportman.nhs. 2014.

22. Wolpert M, Vostanis P, Young S, Clark B, Davies R, Fleming I et al. Child and adolescent mental health services payment system project: final report: London: CAMHS Press. 2015.

23. Wolpert M. THRIVE and Resilience. Young Minds; 11 th February 2015; London. 2015.

24. Hawker DS. Increasing initial attendance at mental health out-patient clinics: opt-in systems and other interventions. Psychiatr Bull. 2007;31(5):179-82.

25. Michelson D, Day C. Improving attendance at child and adolescent mental health services for families from socially disadvantaged communities: evaluation of a pre-intake engagement intervention in the UK Administration and Policy in Mental Health and Mental Health Services Research. 2014;41(2):252-61.

This paper examines a novel intervention to increase engagement with services. It was found that those in the intervention group significantly more likely to attend their appointments.

26. HM Government. Working together to safeguard children: a guide to inter-agency working to safeguard and promote the welfare of children: London: Department for Children, Schools and Families. 2010.

27. Powell C, Appleton JV. Children and young people's missed health care appointments: reconceptualising 'Did Not Attend' to 'Was Not Brought' - a review of the evidence for practice. J Res Nurs. 2012;17(2):181-92.

This paper reviews literature on non-attendance within child and young people health services and suggests a change is needed to 'was not bought' to capture potential safeguarding concerns.
28. Arai L, Stapley S, Roberts H. 'Did not attends' in children 0-10: a scoping review. Child Care Health Dev. 2014;40(6):797-805.

29. Arai L, Stephenson T, Roberts H. The unseen child and safeguarding:'Did not attend'guidelines in the NHS. Arch Dis Child. 2015;1-4.

30. Baruch G, Vrouva I, Fearon P. A follow-up study of characteristics of young people that dropout and continue psychotherapy: service implications for a clinic in the community. Child Adolesc Mental Health. 2009;14(2):69-75.

31. Kim H, Munson MR, McKay MM. Engagement in mental health treatment among adolescents and young adults: a systematic review. Child Adolesc Soc Work J. 2012;29(3):241-66.

32. Luk ES, Staiger PK, Mathai J, Wong L, Birleson P, Adler R. Children with persistent conduct problems who dropout of treatment. Eur Child Adolesc Psychiatry. 2001;10(1):28-36.

33. Miller LM, Southam-Gerow MA, Allin Jr RB. Who stays in treatment? Child and family predictors of youth client retention in a public mental health agency. Child Youth Care Forum. 2008;37:153-70.

34. Stallard P. Parental satisfaction with intervention: differences between respondents and non-respondents to a postal questionnaire. Br J Clin Psychol. 1995;34(3):397-405.

35. Dogra N. What do children and young people want from mental health services? Curr Opin Psychiatry. 2005; 18(4):370-3.

36. Kapur P, Hayes D, Waddingham R, Hillman S, Deighton J, Midgley N. The experience of engaging with mental health services among young people who hear voices and their families: a mixed methods exploratory study. BMC Health Serv Res. 2014;14(1):527.

37. Wolpert M, Hoffman J, Abrines N, Feltham A, Baird L, Law D, et al. Closing the gap: shared decision making in CAMHs. final report for closing the gap through changing relationships. London: The Health Foundation; 2014.

38. Elwyn G, Laitner S, Coulter A, Walker E, Watson P, Thomson R. Implementing shared decision making in the NHS. BMJ. 2010;341:c5146.

39. Westermann GM, Verheij F, Winkens B, Verhulst FC, Van Oort FV. Structured shared decision-making using dialogue and visualization: a randomized controlled trial. Patient Educ Couns. 2013;90(1):74-81.

40. Brinkman WB, Hartl Majcher J, Poling LM, Shi G, Zender M, Sucharew H, et al. Shared decision-making to improve attention-deficit hyperactivity disorder care. Patient Educ Couns. 2013;93(1):95-101. doi:10.1016/ j.pec.2013.04.009.

41. Lindsey MA, Brandt NE, Becker KD, Lee BR, Barth RP, Daleiden EL, et al. Identifying the common elements of treatment engagement interventions in children's mental health services. Clin Child Fam Psychol Rev. 2014;17(3):283-98. 
42. Organization WH. Caring for children and adolescents with mental disorders: setting WHO directions. 2003.

43. Layard R. The depression report: a new deal for depression and anxiety disorders: Centre for Economic Performance, LSE2006.

44. Kelvin R, Layarrd R, York A. Improving Tier 2-3 CAMHS: LSE CEP mimeo. 2009.

45. Stallard P, Udwin O, Goddard MASH. The availability of cognitive behaviour therapy within specialist child and adolescent mental health services (CAMHS): a national survey. Behav Cogn Psychother. 2007;35(4):501-5.

46. Wolpert M, Vostanis P, Young S, Clark B, Davies R, Fleming I et al. Child and Adolescent Mental Health Services Payment System Project: Final Report. Appendix E: Data Analysis. Accessed online at http:// pbrcamhs.org/final-report/. : London: CAMHS Press. 2015.

47. Zarin DA, Pincus HA, West JC, McIntyre JS. Practicebased research in psychiatry. Am J Psychiatr. 1997;154(9):1199-208.

48. McAleavey AA, Lockard AJ, Castonguay LG, Hayes JA, Locke BD. Building a practice research network: obstacles faced and lessons learned at the Center for Collegiate Mental Health. Psychother Res. 2015;25(1):13451.

49. Lambert MJ, Hawkins EJ. Using information about patient progress in supervision: are outcomes enhanced? Aust Psychol. 2001;36(2):131-8.

50. Law D. A practical guide to using service user feedback \& outcome tools to inform clinical practice in child \& adolescent mental health. Some initial guidance from the children and young people's improving access to psychological therapies outcomes oriented practice (COOP) group Department of Health, London. 2012.

51. CYP IAPT National Accreditation Council. CYP IAPT principles in child \& adolescent mental health services values and standards: "delivering with and delivering well”. London: CAMHS Press; 2014.

52. Mulley Al TC, Elwyn, G. Patients' Preferences Matter: Stop the silent misdiagnosis: The Kings Fund: London 2012.

53. Bickman L, Kelley SD, Breda C, de Andrade AR, Riemer $M$. Effects of routine feedback to clinicians on mental health outcomes of youths: results of a randomized trial. Psychiatr Serv. 2011;62(12):1423-9.

54. Weisz JR, Kuppens S, Eckshtain D, Ugueto AM, Hawley KM, Jensen-Doss A. Performance of evidence-based youth psychotherapies compared with usual clinical care: a multilevel meta-analysis. JAMA Psychiatry. 2013;70(7):750-61. doi:10.1001/jamapsychiatry. 2013.1176

55. Manteuffel B, Stephens RL, Sondheimer DL, Fisher SK. Characteristics, service experiences, and outcomes of transition-aged youth in systems of care: programmatic and policy implications. J Behav Health Serv Res. 2008;35(4):469-87.

56. Warren JS, Nelson PL, Mondragon SA, Baldwin SA, Burlingame GM. Youth psychotherapy change trajectories and outcomes in usual care: community mental health versus managed care settings. J Consult Clin Psychol. 2010;78(2):144.

57. Bickman L, Kelley SD, Breda C, de Andrade AR, Riemer M. Effects of routine feedback to clinicians on mental health outcomes of youths: results of a randomized trial. Psychiatr Serv. 2011;62(12):1423-9. doi:10. 1176/appi.ps.002052011.

58. Lambert EW, Doucette A, Bickman L. Measuring mental health outcomes with pre-post designs. J Behav Health Serv Res. 2001;28(3):273-86.

59. Miller SD, Duncan BL, Brown J, Sorrell R, Chalk MB. Using formal client feedback to improve retention and outcome: making ongoing, real-time assessment feasible. J Brief Ther. 2006;5(1):5-22.

60. Monro E. A child centered system: London: The Stationary Office. 2011.

61. Taylor J, Armitage G, Jerwood D, King W, Powley-Baker W. Testing a systems methodology for improving children's safeguarding (summary report). NSPCC. 2013.

62. Armitage G, Taylor J, Ashley L. Systematic assessment in child protection: improving outcomes: Gerry Armitage and colleagues outline how a tool known as failure mode and effects analysis can be used to improve serious case reviews. Nurs Child Young People. 2012;24(2):20-2.

63. Luckock B, Barlow J, Brown C. Developing innovative models of practice at the interface between the NHS and child and family social work where children living at home are at risk of abuse and neglect: a scoping review. Child \& Family Social Work. 2015.

64. Home Office. Multi Agency Working and Information Sharing Project: London: Home Office. 2014.

65. Ofstead. The new Ofsted framework for the inspection of children's services and for reviews of Local Safeguarding Children Boards: an evaluation: Ofstead. 2014.

66. Bevington D, Fuggle P. editors. Supporting and enhancing mentalization in community based teams; The AMBIT approach. Minding the child: mentalization based interventions for children, young people and their families (pp. 163-186). Hove, UK: Routledge; 2012.

67. Bevington D, Fuggle P, Fonagy P, Target M, Asen E. Innovations in pactice: adolescent mentalization based integrative therapy (AMBIT) - a new integrated approach to working with the most hard to reach adolescents with severe complex mental health needs. Child Adolesc Mental Health. 2013;18(1):46-51.

68. Fuggle P, Bevington D, Cracknell L, Hanley J, Hare S, Lincoln $\mathrm{J}$ et al. The Adolescent Mentalization-based Integrative Treatment (AMBIT) approach to outcome evaluation and manualization: adopting a learning organization approach. Clinical Child Psychology and Psychiatry. 2014:1359104514521640.

69. Cooper RL, Meara ME. The organizational huddle process-optimum results through collaboration. Health Care Manager. 2002;21(2):12-6. 
70. Leonard M, Graham S, Bonacum D. The human factor: the critical importance of effective teamwork and communication in providing safe care. Qual Saf Health Care. 2004;13 suppl 1:i85-90.

71. Goldenhar LM, Brady PW, Sutcliffe KM, Muething SE. Huddling for high reliability and situation awareness. BMJ Qual Saf. 2013;22(11):899-906.

72. Brady PW, Muething S, Kotagal U, Ashby M, Gallagher $\mathrm{R}$, Hall D, et al. Improving situation awareness to reduce unrecognized clinical deterioration and serious safety events. Pediatrics. 2013;131(1):e298-308.

73. Situation awareness for everyone (S.A.F.E.). http:// www.rcpch.ac.uk/safe. 6th June 2015.

74. Foulkes $P$. The therapist as a vital factor in side-effects of psychotherapy. Aust N Z J Psychiatry. 2010;44(2):189.

75. Bystedt S, Rozental A, Andersson G, Boettcher J Carlbring P. Clinicians' perspectives on negative effects of psychological treatments. Cogn Behav Ther. 2014;43(4):319-31.

76. Duggan C, Parry G, McMurran M, Davidson K, Dennis J. The recording of adverse events from psychological treatments in clinical trials: evidence from a review of NIHR-funded trials. Trials. 2014;15(1):335.

77.• Linden M. How to define, find and classify side effects in psychotherapy: from unwanted events to adverse treatment reactions. Clin Psychol Psychother. 2013;20(4):286-96.
This paper discusses ways to look at safety and harm in psychotherapy and suggests a model the definition, classification and assessment of psychotherapy side effect.

78. Lingley-Pottie P, McGrath PJ. Telehealth: a child and family-friendly approach to mental health-care reform. J Telemed Telecare. 2008;14(5):225-6.

79. Rozental A, Boettcher J, Andersson G, Schmidt B, Carlbring P. Negative effects of internet interventions: a qualitative content analysis of patients' experiences with treatments delivered online. Cogn Behav Ther. 2015;44(3):223-36.

80. Powell J, Martin S, Sutcliffe P, Todkill D, Gilbert E, Paul $\mathrm{M}$ et al. Young people and mental health: the role of information and communication technology: Warwick Medical School. 2010.

81. Substance Abuse and Mental Health Services Administration. National Mental Health Services Survey (NMHSS): 2010. Rockville, MD2014.

82. Chief Medical Officer's annual report. Public mental health priorities: investing in the evidence, Chapter 6: Department of Health2013.

83. House of Commons Health Committee. Children's and adolescents' mental health and CAMHS: House of Commons. 2015-2015.

84. Department of Health. Data and standards task and finish group report: children and young people's mental health and wellbeing taskforce. London: Department of Health. 2015. 